\title{
Treatment of pityriasis versicolor in the United States
}

\author{
LA Mellen, J Vallee, \\ SR Feldman and \\ $A B$ Fleischer, J $r$
}

Center for Dermatology Research, Department of Dermatology, Wake Forest University School of Medicine, Winston-Salem, , North Carolina, USA

Received 20th September 2002 Accepted 10th March 2004
BACKGROUND: Pityriasis versicolor is a common chronic superficial fungal infection of the skin.

OBJECTIVE: The purpose of this study is to determine the frequency of visits for pityriasis versicolor and to assess how it is currently being treated.

METHODS: Data from the National Ambulatory Medical Care survey were used from the years 1990-1999.

RESULTS: There were 2.9 million visits per year in which pityriasis (tinea) versicolor was listed as a diagnosis; this corresponds to a visit rate of 110 visits per 100000 persons per year. Visit rates varied among racial and ethnic groups, with the highest visit rates for black people and American Indians/Eskimos. A total of $76 \%$ of the medications listed at visits for pityriasis versicolor are FDA approved for the condition; however, many treatments that were prescribed were not.

CONCLUSIONS: Given that as many as one-quarter of treatments prescribed for this easily treatable condition are inappropriate, continued education of medical practitioners concerning appropriate treatment options is needed. ( $J$ Dermatol Treat (2004) 15: 189-192)

Keywords: Fungal infection - Health care delivery - Skin

\section{Introduction}

Pityriasis or tinea versicolor is a common chronic superficial fungal skin infection ${ }^{1}$ caused by the organism Malassezia furfur, which is also known as Pityrosporum ovale or Pityrosporum orbiculare depending on its form. ${ }^{2,3}$ The fungus causes characteristic lesions in susceptible individuals that appear as multiple welldemarcated macules with a fine powdery scale. These lesions may appear hypopigmented in tanned skin, but often appear hyperpigmented in non-tanned skin or on dark-skinned patients. M. furfur is a physiologic skin flora, ${ }^{3,4}$ yet pityriasis versicolor is manifested when conditions favor proliferation of the organism's mycelial form. These conditions include: high temperature and humidity, immunodeficiency or immunosuppression, elevated corticosteroids, and pregnancy. In addition to these factors, there is also thought to be some genetic

\section{Correspondence:}

Steven R Feldman, MD, PhD , Wake Forest University School of Medicine, Department of Dermatology, Winston-Salem, NC 27157-1071, USA. Tel +1336716 7740; Fax $+1 \quad 336716$ 7732; $\quad$ E-mail: sfeldman@wfubmc.edu component to susceptibility to pityriasis versicolor., The lipophilic fungus requires exogenous fatty acids for growth; pityriasis versicolor is therefore a condition seen most often after puberty due to M. furfur's affinity for mature sebaceous glands. Moreover, the lesions are frequently found on the back, upper arms, and trunk where the density of sebaceous glands is high.

Many treatments have been shown to be successful at treating pityriasis versicolor; topical treatment with selenium sulfide $2.5 \%$ is widely recommended. Acceptable alternatives would include topical azole antifungals or oral treatment with ketoconazole or itraconazole, depending on the physician's or the patient's preferences.

While it is recognized that the prevalence of pityriasis versicolor in hot tropical zones with humid climates is approximately $30 \%,{ }^{7}$ prevalence in the USA, a temperate climate, is likely to be much lower. ${ }^{8}$ In fact, US National Health Survey data from 1971 to 1974 showed a prevalence of $0.8 \%$ among in people 1-74 years old $;{ }^{9}$ other sources have reported a similar prevalence of $1-2 \%$ in temperate zones. ${ }^{10-12}$ However, neither the frequency in which people seek care for 
pityriasis versicolor nor the frequency of various treatments used to treat this condition has been assessed.

The goal of this study is to describe the use of physician services for pityriasis versicolor in the US population as a whole, as well as to assess the possible differences among various racial and ethnic groups in this country. In addition, this study will evaluate treatment trends for pityriasis versicolor in the USA and note other diagnoses commonly made concurrently with that of pityriasis versicolor.

\section{Materials and methods}

The National Ambulatory Medical Care Survey (NAMCS) is a national survey of office-based physicians conducted by the Division of Health Care Statistics, the National Center for Health Statistics (NCHS), and the Centers for Disease Control and Prevention. ${ }^{12}$ This survey contains data on individual outpatient visits that are weighted to reflect national estimates describing the use of ambulatory care services in the USA. The physician-patient encounter, or outpatient visit, is the basic sampling unit for the NAMCS. Non-federal physicians classified by the American Medical Association or the American Osteopathic Association as fulfilling office-based patient care and all physician specialties except anesthesiology, pathology, and radiology are included in the NAMCS. For data collection, physicians or office staff complete a patient record form providing the reasons for and duration of the outpatient visit, demographic data, services provided, physician diagnoses, and referral practices. For small practices, $100 \%$ of patient visit data are available. In very large practices, $20 \%$ of visits are included in a random sample. $^{13}$

For this study, we analyzed data collected between 1990 and 1999 for all office visits resulting in the diagnosis of pityriasis versicolor. In order to convert this sample of the population to a national estimate of the prevalence of pityriasis versicolor, each patient record was assigned an inflation factor to adjust for sampling errors; sampling weights are provided in the NAMCS database. These patient visit weights were then applied to estimate the total number of office visits for pityriasis versicolor in the USA. All estimates from the NAMCS are related to the number of patient visits and are subject to sampling variability. This variability is measured using the relative standard of error (SE). The representative relevant SEs for the 1994 NAMCS, the midpoint year for this study, were as follows: $8.1 \%$ for estimates of 10000000 visits, $23.9 \%$ for estimates of 1000000 visits, $33.6 \%$ for estimates of 500000 visits, and $74.8 \%$ for estimates of 100000 visits. SEs for other years of the study were similar and are made available by the NCHS. The NCHS considers an estimate to be reliable if it has a relative SE of less than or equal to $30 \%$ of the estimate. ${ }^{14}$

We estimate the use of medical services for pityriasis versicolor by race and ethnic group as determined by NAMCS data. These frequencies are presented in the form of office visits for pityriasis versicolor per 100000 members of the population for each group. The study also provides an estimate of the percentage of a particular population predicted to be affected by pityriasis versicolor using the number of visits as a proxy for prevalence. All population data were derived from July 1994 US census figures. ${ }^{15}$

In addition to the diagnoses of pityriasis versicolor, the NAMCS records include up to six medications that were used, given, or prescribed at the visit. Because drug treatment may have been used for other conditions when other diagnoses besides pityriasis versicolor were managed at the visit, we analyzed visits at which pityriasis versicolor was the only diagnosis in order to assess what treatments were used. We determined the frequency of prescriptions for pityriasis versicolor and FDA approval status of these medications for the treatment of pityriasis versicolor. ${ }^{16}$

All other diagnoses made during visits at which pityriasis versicolor was diagnosed are ranked in order of frequency and according to their status as primary, secondary, or tertiary diagnoses.

\section{Results}

\section{Frequency of pityriasis versicolor diagnosis}

During the period of 1990-1999, pityriasis versicolor was diagnosed at 2.9 million office visits in the USA, corresponding to a visit frequency of 110 visits per 100000 population per year. A higher visit frequency was identified in black people (140 visits per 100000 / year) and American Indians/Eskimos (150 visits per $100000 /$ year) as compared with white people (110 visits per 100 000/year) and Asian/Pacific islanders (40 visits per $100000 /$ year). The visit rate for Hispanic patients was 110 visits per $100000 /$ year. Most patients in whom pityriasis versicolor was diagnosed were seen by dermatologists $(46 \%)$, followed by family practitioners $(25 \%)$, and pediatricians $(11 \%)$ (Table I). A total of $50 \%$ of patients diagnosed with pityriasis versicolor were male.

\section{Treatment for pityriasis versicolor}

The use of medications was analyzed using visits at which pityriasis versicolor was the only listed diagnosis ( $n=1.2$ million). At these visits, $76 \%$ of the medications listed were FDA approved for pityriasis versicolor. ${ }^{16}$ These medications included ketoconazole (35\%), selenium sulfide $(18 \%)$, clotrimazole $(9 \%)$, miconazole $(4 \%)$, 


\begin{tabular}{lrr} 
Physician & Number $^{\text {a }}$ & Percentage \\
Dermatology & 1,355 & 46.4 \\
Family practice & 724 & 24.8 \\
Pediatrics & 315 & 10.8 \\
Internal medicine & 315 & 10.8 \\
General practice & 143 & 4.9 \\
Other physician & 71 & 2.4 \\
Total & 2922 & 100.0 \\
\hline
\end{tabular}

a Numbers in thousands.

\section{Table I}

Patients diagnosed with pityriasis versicolor by physician type

and econazole (4\%). Listed medications not approved by the FDA for treatment of pityriasis versicolor included a variety of antibiotics, corticosteroids, anti-viral medications, and pain medications. Corticosteroids were not infrequently prescribed for the treatment of this fungal infection; they were included in the treatment in $10 \%$ of patients who were given prescriptions (Table II).

\section{Concurrent diagnoses}

In all, $42 \%$ of patients diagnosed with pityriasis versicolor also had one or two other diagnoses concurrently. There were both dermatologic and non-dermatologic comorbidities. Common comorbid dermatologic conditions included: acne, dermatitis, melanoma, dyschromia, benign neoplasm of skin, seborrheic dermatitis, psoriasis, and dermatophyte infection. Common non-dermatologic conditions included: injury to blood vessels, elective surgery, hypertension, gastroenteritis, upper respiratory tract infection, multiple sclerosis, and HIV infection. The frequency of comorbidities in patients diagnosed with

\begin{tabular}{lrr} 
Treatment & Number $^{\mathrm{a}}$ & Percentage $^{\circ}$ \\
Ketoconazole & & \\
Selenium sulfide & 410 & 34.8 \\
Betamethasone/clotrimazole & 206 & 17.5 \\
Econazole & 66 & 5.6 \\
Miconazole & 44 & 3.7 \\
Clotrimazole & 42 & 3.5 \\
Hydrocortisone & 39 & 3.3 \\
Hydrocortisone/iodoquinol & 30 & 2.5 \\
Imiquimod & 26 & 2.2 \\
Diphenhydramine & 10 & 0.9 \\
Other & 9 & 0.7 \\
Total & 295 & 25.1 \\
\hline
\end{tabular}

${ }^{\mathrm{a}}$ Numbers in thousands.

\section{Table II}

Medications prescribed for patients with pityriasis versicolor as the only diagnosis pityriasis versicolor was similar to that of patients diagnosed with other dermatologic conditions.

\section{Discussion}

Analysis of NAMCS data from 1990 to 1999 found that pityriasis versicolor was diagnosed in 110 per 100000 people in the USA each year. This is lower than expected given that the prevalence of pityriasis in the USA is approximately 1000 per $100000(1 \%){ }^{11,12}$ People afflicted with pityriasis versicolor frequently do not seek care for this condition. However, pityriasis versicolor may be under-diagnosed in patients seen in outpatient settings. As this disease may manifest in various forms (e.g. hyper- or hypopigmentation, with or without a fine scale), it is plausible that physicians often fail to reach the appropriate diagnosis. Misdiagnosis may have implications for treatment, as it would likely lead to excess or inappropriate treatments for this readily treatable condition.

Diagnosis of pityriasis versicolor was more frequent in those who assigned themselves as black people or Native American in comparison with white people. This may reflect a greater susceptibility to pityriasis versicolor in these groups; alternately, there may be greater use of medical services for pityriasis versicolor in these populations due to the greater effect of the disease on pigmentation in populations with darker skin. There is also a greater frequency of seeking medical care for atopic dermatitis in black people compared with white people. ${ }^{17}$ The differences in health care utilization may be due to differences in prevalence of the disease, or it may reflect racial differences in the impact of diseases that affect skin pigmentation. All other racial groups were diagnosed with pityriasis versicolor more frequently than Asian/Pacific islanders. Here again this discrepancy may reflect differences in prevalence of the disease or differences in care-seeking behavior in people who identified themselves in these groups.

The treatment of pityriasis versicolor appears largely appropriate according to our analysis of the NAMCS data. When a treatment was recorded for patient visits in which the only diagnosis was pityriasis versicolor, appropriate medications (i.e. FDA approved for the treatment of pityriasis versicolor) were chosen $76 \%$ of the time; however, in a disturbing $20 \%$ of cases, antibacterials or antivirals, pain medications, or corticosteroids were given. While it may be the case that these treatments were actually prescribed for diagnoses that were not recorded for that visit, it is also likely that inappropriate treatments were often prescribed to treat pityriasis versicolor. Inappropriate treatment for benign conditions such as pityriasis versicolor not only increases the cost of medial care but also risks harming the patient. This is especially true in the case of corticosteroids, which may exacerbate the condition. ${ }^{6}$ 
Hydrocortisone was prescribed in nearly 30000 visits where pityriasis versicolor was the only diagnosis. Moreover, antifungals were frequently used in combination with steroids. For example, in over 66000 visits for pityriasis versicolor, patients were treated with a betamethasone dipropionate/clotrimazole combination. This high-potency steroid combination is not indicated for treating pityriasis versicolor, especially given that there is no significant inflammatory component to the condition and there is the potential for inducing atrophy with a high-potency topical corticosteroid.

Future research may focus on the impact that pityriasis versicolor has on the quality of life of patients with the condition. Further study would also be required to determine whether differing rates of diagnosis of pityriasis versicolor among racial and ethnic groups reflect a true difference in prevalence of disease or simply a difference in health care-seeking behavior for the condition. Education of health care providers on the sundry presentations of this condition and on techniques to properly diagnose pityriasis versicolor, such as conducting a $\mathrm{KOH}$ preparation of the fine scale to see the characteristic 'spaghetti and meatballs' appearance of $M$. furfur, would help minimize the under-diagnosis of this easily treatable condition. The frequent use of topical corticosteroids in the treatment of pityriasis versicolor indicates the need for continued education among ambulatory health care providers concerning appropriate treatment for this common, easily treated skin condition.

\section{References}

1. Roberts SOB, Pityriasis versicolor: a clinical and mycological investigation. Br J Dermatol (1969) 81: 315-26.

2. Tanaka M, Imamura S, Immunological studies on Pityrosporum genus and Malassezia furfur. I Invest Dermatol (1979) 73: 321-4.

3. Schmidt A, Malassezia furfur: a fungus belonging to the physiological skin flora and its relevance in skin disorders. Cutis (1997) 59: 21-4.

4. Roberts SOB, Pityrosporum orbiculare: incidence and distribution on clinically normal skin. $\mathrm{Br} J$ Dermatol (1969) 81: 264-9.

5. Burke RC, Tinea versicolor: susceptibility factors and experimental infection in human beings. J Invest Dermatol (1961) 36: 389-402.

6. Rippon JW, Superficial infections, pityriasis versicolor. In: Medical Mycology: The Pathologic Fungi and the Pathologic Actinomycetes, 3rd edition. Saunders: Philadelphia, 1988: 154-158.

7. Roberts SOB, Pityriasis versicolor. In: Verbow JL, ed. Superficial Fungal Infections: New Clinical Applications in Dermatology. MTP Press: Lancaster, 1986: 47-72.

8. Fagermann J, Epidemiology and ecology of pityriasis versicolor in Europe: treatment and prophylaxis. In: Meinhof W, ed. Oral Therapy in Dermatomycoses: A Step Forward. Symposium Proceedings; Frankfurt; February 1985. The Medicine Publishing Foundation: Oxford, 1985: 89-95.
9. Johnson MLT, Skin conditions and related need for medical care among persons 1-74 years. Series 11, No. 212, DHEW pub. No.79-1660. US Department of Health, Education, and Welfare: Washington, DC, November 1978.

10. Fitzpatrick TB, Johnson RA, Wolff K, Suurmond D, Color atlas and synopsis of clinical dermatology: common and serious diseases. McGraw-Hill: New York, 2001: 722-5.

11. Lookingbill D, Marks J, Principles of dermatology. WB Saunders: Philadelphia, 2000: 225-8.

12. Tenney JB, White KL, Williamson JW, National Medical Ambulatory Medical Care Survey: background and methodology. National Center for Health Statistics: Hyattsville, MD, 1974: 2.

13. 1990 National Ambulatory Care Survey, public use data tape documentation. Centers for Disease Control. US Department of Health and Human Services, Public Health Service: Hyattsville, MD: 1992.

14. National Medical Ambulatory Care Survey, Relative SE documentation. Available at: ftp:///ftp.cdc.gov/pub/ HealthStatistics/NCHS/DatasetDocumentation/NAMCS/

15. US Census Bureau, Resident population estimates of the United States by sex, race and Hispanic origin: April 1, 1990 to July 1, 1999, with short-term projection to November 1, 2000. Available at: http://www.census.gov/

16. Food Drug Administration, Relative drug approval information. Available at: http://www.fda.gov/

17. Janumpally SR, Feldman SR, Gupta AK, Fleischer AB, Jr, In the United States, blacks and Asian/Pacific islanders are more likely than whites to seek medical care for atopic dermatitis. Arch Dermatol (2002) 138: 634-7. 
Copyright of Journal of Dermatological Treatment is the property of Martin Dunitz Publishers and its content may not be copied or emailed to multiple sites or posted to a listserv without the copyright holder's express written permission. However, users may print, download, or email articles for individual use. 